\title{
A cartografia e a formação dos impérios ibéricos na época renascentista
}

\section{Cartography and the formation of Iberian empires in the Renaissance era}

\author{
Alisson Eugênio: \\ Doutorado, Unifal-MG, Brasil \\ alissoneugenio@yahoo.com.br
}

Altino Sérgio Dias de Oliveira:

Mestrado, Unifal-MG, Brasil

altinooliveiro86@gmail.com

\begin{abstract}
Resumo
Esse estudo visa compreender como os mapas produzidos pelos cartógrafos ibéricos, especialmente os portugueses, foram utilizados no processo de formação dos seus impérios ultramarinos. Para isso, será feita uma articulação entre a história da expansão de Portugal e a produção cartográfica que se lhe seguiu, para mostrar que tal produção serviu à coroa portuguesa como instrumento para legitimar as suas conquistas, especialmente no continente americano, e como arma ideológica na geopolítica da aurora da Idade Moderna.
\end{abstract}

Palavras-chave: cartografia, representação, império ibérico, fronteiras coloniais; Renascença

\begin{abstract}
This study aims to understand how the maps produced by Iberian cartographers, especially the Portuguese, were used in the process of formation of their overseas empires. To this end, an articulation will be made between the history of Portugal's expansion and the cartographic production that followed it, to show that such production served the Portuguese crown as an instrument to legitimise its conquests, especially in the American continent, and as an ideological weapon in geopolitics of the dawn of the Modern Age.
\end{abstract}

Keywords: cartography, representation, Iberian empire, colonial borders, Renaissance.

\section{INTRODUÇÃO}

Ao longo da história, os mapas desempenharam funções de grande importância, tanto como representação espacial, quanto como instrumento político, e por isso tem muito a nos dizer sobre a relação humana com o espaço e sobre o tempo dos povos que os produziram. Por isso, são recorrentemente utilizados como documentos, sobretudo pelos historiadores, mas como objeto ainda não são estudados com a abundância como poderiam. Além disso, geralmente são percebidos como uma estrutura unívoca, objetiva e neutra, o que limita a possibilidade de sua compreensão como um artefato complexo, com inúmeras possibilidades de reflexão sobre diversas faces da experiência social, como a que neste texto será discutida.

Para isso, tomaremos como orientação as proposições de alguns teóricos, principalmente as do geógrafo e historiador da cartografia John Brian Harley, para quem os mapas não devem ser compreendidos simplesmente "como levantamentos inertes de paisagens morfológicas ou como 
reflexos passivos do mundo dos objetos, e sim como imagens que contribuem para o diálogo num mundo socialmente construído," uma vez que são construções sociais expressadas através de uma linguagem cartográfica, uma linguagem gráfica que necessita, assim como uma pintura, ser decodificada (HARLEY, 2013, p. 40).

Seguindo essa linha de abordagem, Antonio Sánchez, outro teórico que ajudará a embasar esse estudo, completa afirmando que dessa maneira, como uma construção social, "os mapas antigos passam a ser concebidos como metáforas de domínio, controle e poder sobre o mundo, como alegorias imperiais e não somente como imagens físicas de um lugar" (SÁNCHEZ, 2013, p. 40).

Assim, podemos considerar que, durante a experiência humana no tempo, os mapas foram utilizados como instrumentos discursivos que permitem o exercício do poder de um lugar sobre o outro, e desse modo, a posse deles significava possuir a terra, o que quer dizer que construí-los constitui-se então em um ato de fabricar o poder, "de gerar um panóptico espacial, de apropriar-se do mundo, discipliná-lo e normalizá-lo" (HARVEY, 2005, p. 41).

Com base nessas considerações, este estudo será conduzido com o objetivo de compreender mapas produzidos pelos Estados Modernos ibéricos durante o período 1415 a 1580 como instrumento político no processo de consolidação de seus poderes, tanto nacional, quanto internacionalmente, de expansão territorial e de disputas pelas fronteiras coloniais no Novo Mundo.

\section{O PONTO DE PARTIDA TEÓRICO}

A partir de autores como Erwin Panofsky, Roland Barthes, Michel Foucault e Jacques Derrida, Harley formulou um novo programa para a cartografia histórica. Tendo como um dos seus principais aportes teóricos o conceito de desconstrucionismo proposto por Jacques Derrida, o teórico passou a defender a ideia de que os mapas são imagens que carregam uma construção textual. Para ele, a constituição de um texto não é definida apenas por elementos linguísticos, pois deve-se levar em consideração as suas condições de produção. Desse modo, os mapas, como construções que empregam um sistema de signos, tornam-se um texto, razão pela qual a cartografia é conceituada pelo autor como um discurso - um sistema que dispõe de um conjunto de regras para a representação do conhecimento intrínseco às imagens que definimos como mapas e atlas (HARLEY, 2009 p. 72).

Assim, ao considerar os aspectos retóricos e subjetivos dos mapas, tal autor salienta que é extremamente necessário pesquisar de forma mais aprofundada o contexto histórico específico em que os mapas foram elaborados, a fim de perceber as operações de poder inerentes ao discurso cartográfico e, consequentemente, os efeitos desse poder sobre a sociedade. Além disso, ele destaca 
também que o poder é exercido por meio da cartografia de forma externa e interna. O poder externo é aquele que age através da relação entre o produtor e o contratante de um mapa. Já o poder interno é algo intrínseco aos mapas, sendo exercido através dos elementos cartografados. Então, conforme consideração de outro teórico da relação entre poder e cartografia, "esses dois poderes [o interno e o externo] são indissociáveis, pois só a partir do poder interno é que o poder externo pode existir, já que é o tratamento das técnicas e dos elementos representados que possibilita diversas expressões de um mesmo espaço" (GIRARDI, 2011, p.59).

Por isso, o conceito de representação será útil neste estudo para compreender como os mapas foram construídos e, muitas vezes, manipulados pelos ibéricos a fim de consolidar o seu poder na geopolítica internacional e seu domínio no Novo Mundo, tendo em mente que os mapas transmitem uma ideia do espaço que foi representado para cumprir sua função original: representar um recorte na superfície do planeta.

Contudo, essa ideia, muitas vezes, está contaminada por ideologias, interesses e manipulações políticas, conforme explica Chartier (2002, p. 17):

As representações do mundo social assim construídas, embora aspirem à universalidade de um diagnóstico fundado na razão, são sempre determinadas pelos interesses de grupo que as forjam. Daí, para cada caso, é necessário relacionamento dos discursos proferidos com a posição de quem os utiliza. As percepções do social não são, de forma alguma, discursos neutros: produzem estratégias e práticas (sociais, escolares, políticas) que tendem a impor uma autoridade à custa de outros, por elas menosprezados. Tendem a legitimar um projeto reformador ou a justificar, para os próprios indivíduos, as suas escolhas e condutas. Por isso, esta investigação sobre as representações supõe-nas como estando sempre colocadas num campo de concorrências e de competições cujos desafios se enunciam em termos de poder e dominação. As lutas de representações têm tanta importância como as lutas econômicas para compreender os mecanismos pelos quais um grupo impõe, ou tenta impor, a sua concepção do mundo social, os valores que são seus, e o seu domínio.

\section{A EXPANSÃO MARÍTIMA PORTUGUESA: O NASCIMENTO DE UMA NOVA IMAGEM DO MUNDO}

A expansão marítima portuguesa, iniciada no século $\mathrm{XV}$, ocorreu a partir de um conjunto de múltiplos fatores (sendo os principais: posição geográfica favorável, investimento em estudos de navegação e vontade política dos soberanos) que permitiram a um pequeno reino expandir-se pelo mundo ao longo dos séculos XV e XVI (BARRETO, 1983), aos quais, afirma Boxer também devem ser acrescentados os fatores religiosos e econômicos, "nem sempre, dosados nas mesmas proporções" (2012, p. 33).

A esse respeito, Alencastro lembra-nos de uma problemática geopolítica de grande relevância como fator motivacional, pois os portugueses começaram a se expandir para o mundo a partir de um período marcado pela pressão política castelhana, uma vez que a possibilidade de uma indesejada incorporação a Castela, devido a problemas de sucessão na casa de Borgonha, acabou 
levando à aclamação do Mestre D. João de Avis como novo rei de Portugal (1998, p. 193-207). E foi nesse cenário de fortes instabilidades e de apreensões, a recém-instaurada casa de Avis engendrou um expansionismo preventivo, conquistando territórios além-mar, ao passo que na primeira metade do século XV, Portugal já havia ocupado as ilhas atlânticas da Madeira e os Açores.

Sendo assim, o projeto expansionista empreendido pela nova casa reinante foi instaurado como uma medida estratégica para modificar a imagem que os portugueses haviam construído frente ao seu governo: a de um rei bastardo. Em relação a isso, Thomaz afirma que, de início, a política de expansão, essencialmente, foi concebida "como uma forma de contentar a fidalguia e aliviar a pressão que esta exercia sobre a realeza; a possibilidade de fazer do expansionismo um meio de fortalecer o Estado e afirmar a dinastia só aos poucos se lhe deve ter desenhado" (1998, p. $60)$.

Aponta-se, unanimemente, a conquista da cidade marroquina de Ceuta, tomada em 1415, por uma expedição comandada pelo próprio rei D. João I, como o marco fundador da expansão ultramarina portuguesa, apesar das divergências entre muitos de seus intérpretes. Durante o século XIX, os historiadores analisavam o evento a partir de uma perspectiva nacionalista, engrandecendo os feitos realizados pelos portugueses e minimizando as consequências negativas da expansão. No decorrer do século XX, tal ideia não foi abandonada. Os grandes eventos e os heróis nacionais continuam sendo exaltados. Porém, novas abordagens começam a surgir. Os estudiosos desse período passam a discutir os temas referentes à expansão sob uma ótica sociológica da história, procurando compreender as razões que motivaram os portugueses a atacarem a cidade marroquina e, consequentemente, entender as causas que levaram este povo a se aventurar para o além-mar. Um deles, ao fazer a crítica a uma abordagem teleológica da expansão portuguesa, chegou a afirmar que se a conquista de Ceuta "não houvesse seguido a dezenove anos de distância à passagem do Bojador, por certo, que ninguém se lembraria de ver nela mais que uma das várias manifestações do movimento de mutação do equador religioso que era o Mediterrâneo” (THOMAS, 1998, p. 21).

Constata-se, portanto, que a literatura especializada nos assuntos referentes à expansão marítima portuguesa no século XV, independentemente da abordagem trabalhada, o ano de 1415 é consagrado como o marco do processo expansionista português. Para Serrão, um dos autores mais versados nesse tema, a conquista de Ceuta também promoveu a abertura de mais "duas vertentes da Expansão portuguesa: a primeira com a exploração da costa ocidental da África e a segunda com o descobrimento e colonização dos arquipélagos do Atlântico" (1995, p. 15).

Os especialistas nessa matéria são unânimes em apontar o Infante D. Henrique como um dos principais expoentes do projeto expansionista português, porque, logo após a conquista territorial no Marrocos, ele passa a financiar expedições, e, também, incentiva o desenvolvimento 
técnico de instrumentos astronômicos e embarcações, além de articular politicamente as expedições marítimas na primeira metade do século XV, o que o consagrou como Henrique o navegador da lendária Escola de Sagres. Eles são unânimes também em apontar o reinado de Afonso V, $o$ Africano, alcunha dada a ele devido às investidas militares das praças marroquinas de Alcácer Ceguer (1458), Arzila e Tânger (1471), o início de um período em que a exploração marítima é relegada. Um deles, Vitorino Magalhães Godinho, afirma que “com D. Afonso V é instaurado o período áureo dos feitos militares além-estreito e o período morto das descobertas" (GODINHO, 2007, p. 198).

Seu sucessor, D. João II, teria articulado seu projeto expansionista a partir das terras que poderiam ser descobertas ao sul do Atlântico, pelo fato de que durante a definição do Tratado de Tordesilhas, ele, insistentemente, lutou pelo deslocamento do meridiano para o oeste. Afinal, os planos do rei consistiam em assegurar toda a área correspondente desde a América portuguesa à Índia, além de controlar as rotas comerciais ao longo da costa africana. Thomas ressalta que o projeto dele "não se trata exatamente de um projeto colonial, mas antes, de um projeto imperial à maneira medieval," pois, para o autor, as ambições territoriais de Portugal se entrecruzavam com a fixação de criar um bloco cristão para suplantar o bloco islâmico (1998, p. 165). Para que tal tarefa se concretizasse, seria, primeiramente, necessário promover a cristianização da África desde as suas vertentes ao interior, local que, supostamente, estariam localizados os domínios de um reino cristão comandado pelo lendário Preste João.

Ao longo do seu reinado, D. João II adotou medidas importantes que contribuíram para a efetivação do projeto comercial e marítimo português. Com a centralização das expedições marítimas, o monarca lusitano, graças ao navegador Bartolomeu Dias, dobrou pela primeira vez o Cabo das Tormentas em 1488 (assim denominado pela dificuldade em ultrapassá-lo). Deslumbrado com tal feito, ele alimentou fortes esperanças de, enfim, conquistar ás Índias, rebatizando tal Cabo como o "da Boa Esperança". Com a descoberta da extremidade Sul do continente africano, a ideia ptolomaica de que a África se unia ao continente asiático, fazendo do oceano Índico um mar fechado, cai por terra e a imagem do mundo começa a ser alterada. Após a travessia daquele Cabo, os portugueses enviaram embaixadas a Calecut, Ormuz e Sofala, promovendo a abertura das rotas comerciais para as Índias. Já no Atlântico, tal monarca estabeleceu o monopólio do ouro, escravos e especiarias, bem como construiu a fortaleza de São Jorge da Mina, instalou feitorias ao longo da costa africana e efetuou o povoamento das ilhas de São Tomé e Príncipe.

Por isso, a historiografia portuguesa consagrou, quase ao ponto da mitificação, o reinado de D. João II como o período no qual Portugal atingiu o apogeu da política expansionista. E isso foi possível, entre outros fatores, à sua atuação nas questões diplomáticas envolvendo a chegada de Cristóvão Colombo na América em 1492. Cabe lembrar que com a descoberta do "Novo Mundo", 
por uma expedição financiada por Castela, a coroa portuguesa sentiu-se ameaçada. Tanto que, no ano seguinte, as duas coroas ibéricas se reúnem para partilhar o mundo sob a tutela do papa Alexandre VI. Em 1494, o Tratado de Tordesilhas estava assinado, concedendo a Portugal o direito sobre todas as terras descobertas que estivessem a leste do meridiano, e, para a Espanha, todas as terras a oeste. Por meio do acordo, o reino português estabeleceu, também, o monopólio comercial do Atlântico até o oceano Índico, o que foi crucial para o futuro português.

Depois de tantos feitos, D. João II contribuiu para uma forte afirmação de poder, consolidando as bases de um Estado Moderno em Portugal. Entretanto, o monarca não viu grande parte de seus planos serem concretizados, deixando para seu primo e sucessor, D. Manuel I, a realização do seu maior desejo: a chegada às Índias.

Dando continuidade ao projeto joanino, D. Manuel I participou ativamente nos processos relacionados aos descobrimentos e ao estabelecimento das redes comerciais com as Índias conectando várias partes do mundo. As ações empreendidas por ele privilegiaram a expansão para além do oriente. Tanto que, nos primeiros anos do século XVI, os portugueses já haviam acumulado um número grande de vitórias pelos mares asiáticos, criando um verdadeiro império marítimo que abraçava os quatro cantos do mundo. Entretanto, Portugal, durante o primeiro século de seu expansionismo, adotou uma política pautada na manutenção e controle dos circuitos mercantis, instalando feitorias e fortalezas pela costa do continente africano e asiático, ligando pontos distintos dos quatro continentes. Desse modo, ressalta-se que os lusitanos, até então, apesar de terem estruturado uma importante rede comercial intercontinental, não haviam realizado e efetivado conquistas territoriais importantes e nem sequer tinham desenvolvido uma política colonial, pois da Guiné ao Índico, as fortalezas lusas não correspondiam a conquistas militares. Eram guarnições fortificadas, destinadas a proteger o trato oceânico, porque os portugueses não se arriscavam pelo interior, negociavam nas praias (FURTADO, 2017).

No entanto, a partir de 1509, com a posse de Afonso de Albuquerque no governo do Estado português na Índia, iniciou-se uma mudança na velha política comercial, quando ocorrem as primeiras investidas militares no oriente, conquistando a cidade de Goa. A incorporação dessa localidade contribuiu para a introdução de um novo paradigma de presença dos portugueses pelo mundo, abrindo novos horizontes, estratégias e práticas de expansão marítima. Posto isto, Thomaz declara que "Albuquerque construiu para D. Manuel um verdadeiro império marítimo na Ásia e deu à presença portuguesa no Oceano Índico a forma definitiva, que se manteria por mais de um século com alterações insignificantes.” Esse mesmo autor ressalta, ainda, que a ocupação de Goa em nenhum momento representou a intenção de se construir um império territorial, mas sim um processo gradual de incrementar a territorialidade dos diferentes espaços ligados à rede comercial portuguesa. "Goa é ocupada para fornecer a esta uma capital administrativa em posição central, 
facilmente defensável e autossuficiente em matéria de abastecimento e víveres. As demais posições em terra são-no ou para assegurar a articulação da rede com os espaços abastecedores e consumidores", de modo que a territorialidade pudesse exercer "um fim instrumental" (1998, respectivamente p. 197 e 214-215).

Assim, se o projeto expansionista de D. Manuel I sempre esteve vocacionado para o mar, as medidas de ocupação territorial iniciadas por Afonso de Albuquerque podem ser consideradas um dos pilares da política empreendida pelo seu sucessor, D. João III, que nesse assunto adotou medidas mais concretas, menos idealistas (referentes ao messianismo de seu antecessor). Fato que pode ser justificado pela conjuntura complicada que se estendia pelo Reino e por toda Europa no período em que subiu ao trono. A Coroa necessitava resolver problemas graves que variavam desde as recorrentes secas à peste. Economicamente, Portugal passava por uma severa crise decorrente dos altos investimentos necessários para a manutenção e administração do império ultramarino.

Além disso, a monarquia enfrentava algumas tensões políticas geradas pela contestação do rei francês Francisco I em relação à divisão do mundo pelos ibéricos celebrada no Tratado de Tordesilhas, bem como do rei espanhol Carlos V que abriu uma discussão sobre a posse das ilhas Molucas e a demarcação do antimeridiano. E isso, em um cenário continental marcado por acontecimentos que agitaram a geopolítica europeia, como a Reforma Protestante que acabou sendo um dos fatores determinantes para a eclosão de diversas guerras em tal continente.

O projeto expansionista de D. João III sofreu significativas alterações. Durante o seu reinado, as rotas para oriente não foram mais encaradas como uma estratégia para a conquista de Jerusalém; passaram a ser analisadas somente pelo viés econômico. A partir dos anos trinta do século XVI, a manutenção dos territórios portugueses nas Índias começou a se desgastar. Os altos investimentos, a desorganização administrativa, a dificuldade em recrutar militares e homens para as demais funções, associados à longa distância entre Portugal e a Ásia, contribuíram para uma reorientação da expansão marítima portuguesa. Ao contrário de seu pai, que não voltou o seu olhar para a América, ele viu no Novo Mundo uma nova alternativa econômica para resolver os problemas da Coroa, dando início a colonização e exploração do litoral do território descoberto por Pedro Alvares Cabral em 1500, com a criação das capitanias hereditárias e a instauração do governo geral.

$\mathrm{Na}$ Índia, apesar das adversidades, aquele monarca insiste em dar continuidade à política de territorialidade iniciada por Afonso de Albuquerque durante o reinado de D. Manuel; política continuada por D. Sebastião, que durante o seu reinado também se empenhara na criação de um Império português no norte da África, visando combater os mouros e ampliar os domínios controlados pela fé cristã, fato este que, segundo Buescu, foi retomado em decorrência de "um conjunto de valores, ressentimentos e projetos que habitaram as almas dos portugueses a partir da 
segunda metade do século XVI” ( 2008, p. 89). Com a morte inesperada desse soberano na batalha de Alcácer-Quibir, quando tinha apenas 24 anos de idade, a monarquia portuguesa perde a sua linha sucessoria, pois o jovem rei não deixará herdeiros. Assim, no ano de 1580, ocorre a anexação de Portugal pela Espanha.

Os portugueses, ao longo dos séculos XV e XVI, promoveram a abertura do mundo, ampliando os limites da Terra, utilizando a cartografia como um dos elementos fundamentais para o sucesso dos seus "descobrimentos" (CANAS, 2003). Foi com base nela, entre outros fatores, que eles que inauguraram, segundo Barreto, novas modalidades de comunicação inter-civilizacional, levando os europeus a se auto-afirmarem como a civilização dominante frente à realidade natural e humana. Conforme suas palavras, foram eles que "realizaram a metamorfose do impossível em possível, do desconhecido em conhecido, ao serem os primeiros a, sistematicamente, enfrentar e transformar o obstáculo de silêncio e medo que é o grande mar oceano em via de comunicação planetária" (1983, p. 10).

\section{A CARTOGREAFIA DA CONQUISTA}

A cartografia foi um dos primeiros instrumentos a serem utilizados pelo homem para impor alguma espécie de ordem e estrutura ao espaço, pois, por meio de uma abstração da realidade, eles oferecem aos seus observadores a chance de ver determinadas partes do mundo, muitas vezes, inacessíveis. Posto isto, Brotton observa que, mesmo nos dias de hoje, o viajante mais dedicado não irá conseguir conhecer nada além do que uma fração da superfície terrestre de mais de 510 milhões de quilômetros quadrados. Partindo desta compreensão, em paralelo ao século XVI, tal situação era ainda mais complexa. Considerando toda a limitação da época, grande parte das informações referentes aos lugares mais remotos do planeta era compartilhada através dos mapas, e foi desse modo que as terras recém-descobertas tornaram-se acessíveis aos seus futuros soberanos, razão pela qual ele afirma que, ao elaborarem mapas, “os cartógrafos não apenas reproduzem o mundo, eles o constroem" (2012, p. 14).

Portanto, com a expansão marítima europeia, um mundo novo começou a ser traçado a partir da régua, do esquadro e do compasso de um cosmógrafo, que, muitas vezes, manipulava os atributos cartográficos de acordo com os ideais políticos, religiosos e econômicos de suas coroas.

Devido isso, os mapas começavam a ser mantidos sob o maior sigilo possível, à medida que as disputas territoriais e os conflitos geopolíticos aumentavam. Por isso, os que foram produzidos para representarem as terras então descobertas foram convertidos em objetos muito cobiçados e valorizados pelos contrabandistas, acirrando, ainda mais, as disputas travadas pelas 
principais nações, já que as informações por eles reveladas eram vitais para o fortalecimento e continuidade do empreendimento colonial, principalmente, dos reinos ibéricos.

Com a incorporação de novos continentes, a partir do século XVI, a concorrência desmedida pelas novas terras leva os reinos nela envolvidos a se interessarem, demasiadamente, pelo conhecimento geográfico desses locais, razão pela qual as produções cartográficas foram fundamentais para sustentar as pretensões territoriais e resolver litígios de fronteira. Pois, segundo Harley, possuir o mapa era como possuir a própria terra por ele representada, (HARLEY, 2009, p.18), o que permite compreender, em grande parte, o porquê das monarquias ibéricas terem feito da cartografia uma arma para resolver as suas questões geopolíticas, ao transformarem os mapas em instrumentos jurídicos e de poder que serviram para autenticar e legitimar a posse sobre as áreas descobertas.

Consequentemente, pode-se afirmar que, durante o período dos descobrimentos, o ato de se produzir um mapa se configurava em um exercício de poder. E isso quer dizer que quando uma descoberta geográfica era representada cartograficamente, a sua representação é uma das expressões (como prática intrínseca à conquista) do exercício do poder sobre o território, da territorialidade que sobre ela passava a ser exercida.

Isso explica o fato de que os cartógrafos ficavam, antes de tudo, bem mais preocupados em registrar a existência de um novo lugar descoberto em vez de dar a ele sua forma precisa (BLACK, 2005), possibilitando compreender o fato de os mapas terem sidos utilizados para expressar o poder e controle sobre os espaços, criando, assim, uma ligação entre eles e os territórios representados. Portanto, a cartografia foi um instrumento importantíssimo para legitimação e exercício do poder sobre o território.

Desse modo, as produções cartográficas podem ser compreendidas como emissores de discursos de intencionalidades, pois buscam reforçar a autoridade desejada em relação ao espaço que se pretende territorializar, dominar e, enfim, legitimar. Assim, os mapas se constituíram como um importante meio de assimilação das possessões territoriais do Novo Mundo. Isso porque, a sociedade europeia, da época dos grandes descobrimentos, juridicamente não aceitava provas inteiramente em testemunhos verbais, motivo pelo qual os registros escritos ou gráficos foram transformados em um ato político estratégico, principalmente nas controvérsias geopolíticas envolvendo disputa por território, uma vez que eles eram portadores de grande autoridade e, com efeito, poderiam conferir maior legitimidade à posse reivindicada.

No entanto, tal ato político não era uma tarefa simples. Ao passo em que os contornos do mundo eram redesenhados, a sua superfície foi sendo transformada em um tabuleiro de um jogo arriscado, em que uma "jogada" mal articulada era sinônimo de perdas incontáveis. Nesse cenário de risco, as grandes nações envolvidas no processo de dominação do Novo Mundo passaram a 
utilizar todos os atributos cartográficos em apoio aos seus interesses e, consequentemente, uma verdadeira batalha se acirrava cada vez mais e a cartografia passava a ser uma das peças mais valiosas, a que fornecia as melhores condições de se conquistar a vitória no plano diplomático e jurídico. E foi por esse motivo que a geometria, os símbolos, as cores, a projeção, enfim, todos os elementos constituídores de um mapa passaram a ser manipulados gerando mensagens e discursos ideológicos que eram, constantemente, explorados pela política colonialista, levando Lestringant a concluir que a cartografia renascentista passou a forjar as fronteiras naturais dispondo do futuro dos povos, remodelando a estrutura dos continentes e controlando calculadamente o espaço (2009).

Dessa maneira, os mapas da Europa renascentista, além de facilitarem o controle das terras distantes, proporcionaram maior conhecimento e poder para as pessoas que nunca haviam visto estes lugares. Assim, os "senhores, sem sair da biblioteca real, podiam apenas com os olhos percorrer os territórios incorporados, estudar os problemas administrativos ou elaborar estratégias visando intensificar o controle estatal" (QUADROS, 2008, p. 30).

E isso evidencia uma das muitas operações de poder que podem ser executadas através de um mapa, sobretudo em uma época em que o capitalismo, ao tornar-se, aos poucos, o modo de produção predominante na formação social europeia, acabou concorrendo para que a representação do território passasse a ser um dos principais meios para a institucionalização da propriedade, permitindo ao Estado produzir um discurso espacial conveniente as suas pretensões.

As mudanças políticas, intelectuais, teológicas e geográficas, a partir do Renascimento, tornaram-se velozes demais para serem assimiladas e sistematizadas pela comunidade erudita da época, gerando, assim, uma ruptura dos padrões cosmográficos da qual o mundo era representado e compreendido. O geógrafo David Harvey compreende que essas mudanças foram fortemente aceleradas em decorrência de uma nova mentalidade influenciada pelos princípios capitalistas que se configurava. Com isso, a concepção cosmográfica definhou, passando a ser substituída por uma cartografia estratégica amparada por uma geografia forçada a administrar impérios, mapear e planejar o uso da terra e os direitos territoriais, bem como coletar e analisar dados úteis para fins de negócios e de administração estatal. Com a consolidação da economia capitalista mercantil, ele observa que as influências dessa nova estrutura política e social acarretaram o fortalecimento da interligação entre o dinheiro, tempo e espaço, o que favoreceu a manutenção do poder político, que foi, racionalmente, trabalhado por meio do calendário, do relógio e pelos mapas (HARVEY, 1992).

Em outros termos, John Brian Harley, refletindo sobre essa questão, salienta que "pode-se igualmente considerar que os mapas são parte integrante de algumas mudanças estruturais de longo prazo que marcaram a passagem do feudalismo ao capitalismo. Pois, a economia mundial e sua nova divisão geográfica do trabalho foram produzidas com a ajuda de documentos geográficos, 
incluídos os mapas," o que permite concluir que, assim como o relógio introduziu a "disciplina do tempo", as linhas dos mapas introduziram uma "disciplina do espaço" (HARLEY, 2009, p. 8).

Portanto, a sociedade quinhentista, marcada por profundas transformações, em especial a descoberta de uma quarta parte do mundo, passa a ver e representar o planeta de uma forma adaptada às novas estruturas econômicas e políticas que estavam sendo gestadas na dialética das relações humanas, em uma época em que a noção de espacialidade, devido principalmente à referida descoberta, foi reinventada para que o espaço, sob a égide do capitalismo, além de se tornar uma importante mercadoria, adquiriu também uma força política maior, fato que interfere, diretamente, nas funções mais elementares de uma produção cartográfica (HARLEY, 2009, p. 5).

Com a abertura de novas rotas comerciais e, consequentemente, o acirramento da competição internacional pela incorporação de novos territórios, os mapas começaram, gradualmente, a serem elaborados de forma mais funcional, prática e objetiva. Por isso, essa nova tendência cartográfica, marcada pelo rigor matemático e geométrico, foi determinante no processo de transformação do espaço como uma coisa usável, maleável e, portanto, capaz de ser dominada pela ação humana, o que foi possível, entre outros fatores, com a redescoberta do sistema de coordenadas geográficas de Ptolomeu no século XV que permitiu à geometria fornecer a linguagem básica do discurso cartográfico.

Assim, estavam criadas as condições para os mapas servirem como instrumentos de essenciais na promoção da política colonial. Com efeito, muitos territórios foram reivindicados no papel antes de serem efetivamente ocupados, pois, conforme Harley aponta, a "sintaxe euclidiana" tornou-se a principal estrutura do controle territorial, uma vez que

a natureza gráfica dos mapas permitia aos seus usuários imperiais um poder arbitrário, facilmente dissociado de responsabilidades sociais e suas consequências. Dessa forma, o espaço podia ser dividido sobre o papel, como, por exemplo, ocorreu quando em 1494 as monarquias portuguesas e espanholas, com a benção e o intermédio do papa Alexandre VI, delimitaram as possessões no Novo Mundo (2009, p. 5).

Desse modo, as viagens exploratórias promovidas pelos ibéricos contribuíram, radicalmente, na maneira como os europeus concebiam o espaço e o tempo, levando-os a reconstruírem a sua visão do mundo. De uma perspectiva etnocêntrica, a cultura europeia ocidental passa a ter que refletir sobre os "outros mundos". As quantidades vertiginosas de informações referentes às terras recém-descobertas que chegavam à Europa tiveram de ser, gradualmente, absorvidas e representadas, revelando um globo finito e potencialmente apreensível. 
Então, com base no que foi dito até agora, sobretudo no que diz respeito à discussão sobre a relação entre o poder e o espaço, ${ }^{1}$ a cartografia foi transformada, a partir da época renascentista, mais precisamente no alvorecer da Idade Moderna, em uma importante e eficiente fonte de saber e poder, porque o conhecimento gerado pelas produções cartográficas dificilmente estava dissociado das operações de poder dos nascentes Estados Modernos. Sobretudo depois das grandes descobertas, quando os mapas, além de representar territórios, funcionaram como um meio de legitimar a posse sobre eles.

Isso porque, naquela época, as informações extraídas das representações cartográficas apoiavam, sistematicamente, o exercício do poder do Estado, de modo que os elementos cartográficos eram elaborados visando à expansão da nação por ele governada e, principalmente, para serem utilizados como ponto de apoio diplomático na negociação de tratados, em especial sobre os territórios coloniais.

\section{MAPAS E AS DIFERENTES EXPRESSÕES DO PODER NO CONTEXTO DAS CONQUISTAS IBÉRICAS}

Conforme os contornos do mundo eram redesenhados, Portugal e Espanha ampliavam os seus olhares para os mapas. Em um cenário cada vez mais competitivo, o conhecimento cartográfico tornou-se um dos principais meios para a construção de um Império Ultramarino. Conscientes dessa importância, as monarquias ibéricas adotaram a política do sigilo. Embora ineficaz, os dois reinos traçaram diversas estratégias objetivando monopolizar e resguardar, ao máximo, todo o material que trazia alguma informação pertinente em relação às terras recémdescobertas.

Para tal propósito, foram desenvolvidas em Lisboa e Sevilha, respectivamente, a Casa da Guiné, Mina e Índia e a Casa de la Contratación, centralizando todos os assuntos referentes à navegação e ao comércio externo. Através dessas organizações, começaram a ser produzidos, copiados e impressos os mapas que vieram a ser denominados de "Padrão Real” ou "Padrão

\footnotetext{
${ }^{1}$ Foucault foi um dos pensadores que mais se preocupou com a espacialidade do poder. O autor dizia que "seria preciso fazer uma história dos espaços - que seria ao mesmo tempo uma história dos poderes - que estudasse desde grandes estratégias da geopolítica até as pequenas táticas do habitar" (FOUCAULT, 1989, p. 212). Observa-se que ele, ao discutir sobre as disposições espaciais, as repartições, as espacializações, enfim, sobre as mais variadas abordagens referentes à dimensão espacial do exercício do poder, sempre o faz privilegiando os micro-espaços, tais como: a organização espacial dos hospitais, dos asilos, das escolas, dos quartéis e das fábricas. No decorrer da década de 80, os geógrafos franceses Claval (1979) e Raffestin (1993) começaram a trazer os estudos foucaultianos para o campo da Geografia. Impulsionado por essa perspectiva, Harley (2009) procura adaptar as considerações de Foucault referentes aos micro-espaços para o macro-espaço, defendendo a ideia de que as representações cartográficas sempre estiveram associadas aos grupos dominantes e estes, ao longo da história, fizeram da confecção de mapas uma das armas de inteligência especializadas para adquirir um poder, administrá-lo, codificá-lo e legitimá-lo.
} 
Oficial”. Segundo Sánchez a "padronização cartográfica" foi estabelecida com intuito de fortalecer o projeto político, ideológico e religioso das coroas em questão. Logo, portugueses e castelhanos, tentando legitimar as suas conquistas, foram levados a forjar a ideia de uma cartografia oficial (2013).

Exemplo disso, desde o tratado de Alcáçovas-Toledo em 1479 até ao de Tordesilhas em 1494, além da disputa pelas ilhas Molucas e a demarcação do antimeridiano, entre outros episódios, os padrões reais foram considerados como os principais documentos que os dois adversários políticos aceitavam como juridicamente válidos. Além disso, o autor destaca também que os padrões reais foram utilizados pelos reinos ibéricos a partir de duas categorias específicas. Primeiramente, os mapas eram utilizados de forma mais pragmática, sendo confeccionados de acordo com as necessidades práticas dos pilotos. Já na segunda categoria, os mapas eram inseridos ao espaço da metáfora, da admiração, da reputação, da ostentação, das conotações simbólicas e ideológicas, e, também do figurativo, do alegórico e do emblemático. Com tais características, os exemplares pertencentes à primeira categoria foram praticamente destruídos, dado seu caráter sigiloso, razão pela qual a maioria dos mapas dessa época que resistiram ao tempo corresponde à segunda categoria.

Essa sistematização cartográfica foi fundamental para a expansão dos impérios ibéricos, principalmente no Novo Mundo, pois ao passo que seus limites se ampliavam, os mapas eram instrumentalizados para servirem não somente como uma forma de orientação espacial e como um instrumento de legitimação da conquista após a incorporação de um território por meio de intervenções armadas, mas também como uma espécie de garantia de simbólica de posse.

Essa associação entre o uso prático e simbólico dos mapas tornou-se indispensável para o cumprimento das aspirações expansionistas dos impérios ibéricos. O primeiro pela possibilidade de uma precisão mínima necessária para uma reinvindição/legitimação territorial, e o segundo como uma forma de exercício do poder, do poder simbólico, nos termos de Bourdieu, para quem os mapas através de sistemas simbólicos "cumprem a sua função política de instrumentos de imposição ou de legitimação da dominação" (1989, p. 11). ${ }^{2}$ Desse modo, avalia Sánchez onde o rei não se faz presente fisicamente, "não apenas se ergue um padrão de pedra em sua lembrança, mas também se representa o seu poder em forma de soberania territorial por meio de imagens cartográficas.” Assim, as necessidades imperiais do controle do espaço materializado pelas representações cartográficas proporcionaram a conquista de um novo mundo como imagem. Neste sentido, ele conclui, as monarquias ibéricas, a partir do uso simbólico dos mapas, transformaram em imagem os seus

\footnotetext{
${ }^{2}$ De acordo com ele, o poder simbólico é o poder de constituir o dado pela enunciação, de fazer ver e fazer crer, de se exercer pelo que ele representa, pela sua força de persuasão, p. 14.
} 
ideais. Dessa maneira, as duas nações competidoras construíram "mapas com palavras e discursos com mapas, e com ambos levantaram seus impérios" (2013, p. 146).

\section{A DIVISÃO DO MUNDO ENTRE OS IBÉRICOS: UMA NOVA GEOPOLÍTICA É OLDADA ATRAVÉS DOS MAPAS}

Com a consolidação da geopolítica iniciada com as viagens exploratórias empreendidas pelos portugueses ao longo do século XV, o principal eixo do poder e as principais rotas comerciais foram deslocas do Mediterrâneo para o Atlântico. Com isso, ergue-se um novo cenário internacional marcado por relações conflituosas, a partir das quais, podemos compreender o empenho das coroas ibéricas utilizarem a cartografia como uma ferramneta do seu poder, ao perceberem que as representações cartográficas eram indispensáveis para a regulamentação, sistematização e institucionalização de tratados e acordos diplomáticos.

Sabe-se que, no século XV, Portugal inicia de modo pioneiro a expansão marítima. Tal processo foi amplamente amparado por uma série de documentos elaborados a partir de uma delimitação cartográfica das áreas em disputa. Então, “mais do que expressar rumos, distâncias e coordenadas, a cartografia demarcou as divisões políticas do mundo recém-alcançado pelos portugueses," alicerçando um grande império e sobretudo despertando a competição e ambição de seu vizinho peninsular (LOPES, 2016, p. 171).

Desse modo, podemos observar, a partir das representações cartográficas referentes ao período mencionado, as relacões geopolíticas que se configuravam. Conforme as delimitações geográficas eram expressadas pelos mapas, as disputas, as intenções políticas, comerciais e religiosas ganhavam contornos mais definidos. Assim, tanto o Tratado de Tordesilhas, como a questão das ilhas Molucas e a consequente tentativa de demarcação de uma antimeridiano cruzando o oceano Pacífico expressam o protagonismo adquirido pela cartografia diante das disputas em torno da construção e manutenção dos impérios ultramarinos ibéricos, pois os mapas simplificaram as informações sobre uma determinada região, sintetizando o que era conhecido, compreendido, suposto ou até ignorado acerca de um determinado espaço ou território.

É isso que observamos, por exemplo, nas hostilidades entre portugueses e castelhanos que, embora remontem à Idade Média, é somente nas décadas finais do século XV que uma disputa inédita passaria a ser o foco principal das anteções de ambos os reinos pelos próximos anos. A rivalidade territorial luso-castelhana se deslocava da península para o oceano. O Mare Clausum, que garantia exclusividade ao empreendimento português, seria contestado pela primeira vez. Em quatro de setembro de 1479, firmava-se o Tratado de Alcáçovas-Toledo entre os Reis Católicos da Espanha e Afonso V de Portugal. O acordo visava acabar com as hostilidades provocadas pela Guerra de Sucessão Castelhana (1475-79), iniciada em decorrência da morte do rei Henrique IV de 
Castela em 1474. Com o rei falecido, duas correntes partidárias se estabelecem reivindicando o trono de Leão e Castela: os que defendiam D. Joana, a Beltraneja, filha de Henrique (ou, segundo os mexericos da corte, da rainha,) e os defensores da infanta Isabel, irmã do rei, que acabou herdando o trono de Castela.

Com o Tratado de Alcáçovas retificado em Toledo entre Espanha e Portugal em seis de março de 1480, várias questões foram acordadas. Entre elas, a determinação de uma política referente às navegações pelo Atlântico africano e a distribuição dos territórios, conforme as zonas de influência entre ambos os reinos. Entretanto, nesse período, Portugal já dominava, em grande parte, as ilhas atlânticas e também a costa africana. Diante da assinatura do acordo, a Coroa portuguesa, legalmente, passaria a controlar a Guiné, as ilhas da Madeira e Porto Santo, os Açores e as ilhas de Cabo Verde. Castela exerceria a sua soberania somente sobre as ilhas Canárias.

Com este e outros acordos futuros, longe de alcançar a paz final, tal Tratado levaria a uma longa e controversa disputa entre as duas potências marinhas que só seria resolvida com o Tratado de Limites, não ratificado, de 1750 e formalizado em 1777 com o Tratado de São Ildefonso, de modo que pode-se afirmar que ele foi determinante para a geopolítica colonial ibérica.

Por exemplo, um de seus principais desdobramentos, o estabelecimento de um paralelo ao sul das Canárias, que impedia os castelhanos de navegarem pelas águas do Atlântico, permanecendo então o princípio do Mare Clausum, deixava em aberto a livre navegação pela imensidão do Atlântico ocidental, abalando precocemente em 1493 a paz gerada pelos acordos nele firmados, com a chegada de Cristóvão Colombo ao Novo Mundo.

Essa viagem de Colombo desencadeou outra situação de rivalidades e reivindicações entre as potências ibéricas, sinalizando o fim das alianças firmadas em 1479 em Alcáçovas. A partir de 1493, inicia-se um período marcado por fortes tensões diplomáticas, gerando bulas e mapas, que se revelavam imprescindíveis para resolvê-las.

Extremamente descontente com os resultados expostos pela viagem de Colombo, D. João II enviou um embaixador para Castela com o intuito de lembrar aos Reis Católicos o Tratado de Alcáçovas (1479), alegando que Colombo tinha invadido águas portuguesas. A reivindicação do monarca português baseava-se em uma interpretação da bula Aeterni Regis, ratificada no ano de 1481. Dessa maneira, com o apoio papal, Isabel e Fernando haviam concordado que qualquer novo território descoberto no Atlântico, com exceção das Canárias, pertenceriam a Portugal. Contudo, como aponta Bown (2013, p. 141) "tratados, claro, se baseiam no princípio de que os termos permanecem válidos apenas enquanto os princípios subjacentes continuem substancialmente inalterados." Assim, os soberanos de Castela e Aragão, certos de que essas novas terras, ou a nova rota para Índias, representavam algo inteiramente diferente e imprevisto, poderiam analisá-las fora 
dos limites do tratado. Tal situação marcava o início de uma desgastante batalha diplomática pelas águas do Atlântico, antecipando as descobertas e as conquistas.

Buscando encontrar uma resposta para as questões levantadas pelo rei português, Isabel e Fernando, em abril de 1493, semanas depois da volta de Colombo à Espanha, solicitaram ao papa espanhol Alexandre VI a concessão das ilhas descobertas pelo navegador genovês. No mês seguinte, em favor da sua terra natal, o papa emitiu a primeira de uma série de três famosas bulas, concedendo aos Reis Católicos e aos seus herdeiros em perpetuidade, livre poder, autoridade e jurisdição de todos os tipos sobre a totalidade das novas terras, anulando o monopólio português dos descobrimentos e a possessão das Índias Orientais por completo, deixando Portugal sem os privilégios concedidos pela bula Romanus Pontifex de 1455.

Alexandre VI, evitando um conflito ainda maior entre os reinos ibéricos, alegava que apoiava a Espanha e Portugal igualmente, deixando claro que os portugueses foram beneficiados por ele nas questões envolvendo as minas de ouro da Guiné. Entretanto, o papa, pressionado politicamente pelos monarcas de seu país, produziu mais duas bulas, nos dias três e quatro de maio, como se fossem extensão da bula original. A segunda das bulas alexandrinas, a Eximiae Devotionis, foi uma reformulação da primeira, enfatizando os direitos concedidos a Portugal em anos anteriores e cedendo à Espanha os mesmos direitos atribuídos ao país vizinho sobre as suas descobertas na África. Por esse motivo, a primeira bula, emitida em três de maio de 1493, carecia de argumentos mais científicos e geográficos diante da solicitação castelhana, razão pela qual o papa, recémempossado, emitiu a terceira bula no dia seguinte, legitimando, definitivamente, a propriedade dos territórios descobertos por Colombo a Castela. O novo texto era em parte uma reafirmação da primeira bula, Inter Caetera, destinado a sanar as falhas da bula anterior e a estabelecer, também, a demarcação de uma linha imaginária de polo a polo separando as águas pertencentes a ambos os reinos.

A linha citada no documento pontifício foi a base do Tratado de Tordesilhas, de forma que se a bula Inter Caetera proclamava a soberania de Castela, a seguinte definia as zonas sobre as quais esse poder soberano poderia ser exercido. Após a última bula alexandrina ser concedida em setembro de $1493,{ }^{3}$ ampliando as doações à Coroa castelhana de todos os territórios asiáticos que fossem descobertos a partir do ocidente, as discussões sobre a demarcação de um meridiano, separando as possessões entre os reinos competidores ganham um novo vigor. Entre os meses que iam desde o despacho das bulas papais até o Tratado de Tordesilhas, D. João II tentou de diversas

\footnotetext{
${ }^{3}$ A bula Dudum Siquidem, datada de 26 de setembro de 1493, é considerada, por muitos autores, como uma reafirmação da bula Inter Caetera, de 4 de maio. Esse novo documento concedia à Espanha direito sobre todas as terras a oeste e a sul, assinalando até a Índia como terra aberta aos espanhóis. Reafirmava também que os navios de nenhuma outra nação deviam navegar, explorar ou até pescar nessas águas sem permissão por escrito, "mesmo por motivos de caridade ou fé", e que os monarcas espanhóis e português iriam mantê-las (as terras) para sempre defende-las contra quem se opusesse (BOWN, 2013, p. 152).
} 
formas diminuir os impactos provocados pelos documentos expedidos por Alexandre VI. Tanto que o rei português, insistentemente, solicitava aos Reis Católicos a modificação da posição do meridiano, transladando-o mais para o oeste em relação ao que havia sido estipulado na segunda bula de maio de 1493, enquanto Fernando e Isabel organizavam uma junta cosmográfica, reunindo diversos documentos entre mapas e outros instrumentos para legitimar as suas reivindicações.

Diante disso, percebe-se o quanto os estudos cosmográficos foram determinantes na solução dos problemas políticos gerados pelas viagens de Colombo. A esse respeito, afirma-se que a carta de marear, elaborada pela equipe de Colombo para representar as ilhas descobertas, é retratada pela historiografia espanhola como um dos principais documentos utilizados no processo de efetivação do Tratado de Tordesilhas. O autor também afirma que, para os estudiosos portugueses, os mapas produzidos por parte dos cosmógrafos do rei D. João II tiveram o mesmo peso do que as produções do reino vizinho. Eles alegam que grande parte das cartas confeccionadas a mando do soberano lusitano foram influenciadas pela carta de marear de Pêro da Covilhã, ${ }^{4}$ enviada a Portugal ao rei em 1491 e que ela ajudou a sustentar a ideia joanina de demarcar o meridiano a 370 léguas das ilhas de Cabo Verde. Dessa maneira, a carta de Colombo e a de Covilhã, "constituem um exemplo esclarecedor do que François Dainville denominou de cartografia jurídica," isto é, "aqueles mapas levantados em contexto de tensão diplomática e de litígio que foram utilizados como provas testemunhais em juízos ou na resolução de uma disputa geográfica,” (SÁNCHEZ, 2013, p. 97), o que permite afirmar que os mapas jurídicos foram os principais argumentos materiais, exercendo a capacidade de representar o poder e os direitos de um soberano sobre os espaços conquistados.

Após as deliberações papais, as negociações entre as duas potências prosseguiram. Em março de 1494, as delegações de Portugal e Espanha reuniram-se na cidade de Tordesilhas. Depois de três meses de discussões, no dia sete de junho, os países conflitantes chegaram a um acordo histórico conhecido como Tratado de Tordesilhas. Preservando em grande parte as prescrições das bulas concedidas no ano anterior, poucos itens foram acrescentados. Entre essas novidades, ficou decidido que, dentro de dez meses a partir da assinatura do tratado, ambos os países deveriam despachar navios com especialistas em navegação e cosmografia para se encontrarem nas ilhas de Cabo Verde, com o propósito de se determinar a localização da fronteira em alto mar. Posteriormente, com a demarcação da fronteira, seria produzido um mapa, representado o meridiano separando os interesses territoriais entre portugueses e espanhóis.

\footnotetext{
${ }^{4}$ Em 1487, D. João II enviou Pêro da Covilhã, juntamente com Afonso de Paiva, para uma longa missão no oriente. Disfarçados de mercadores e treinados por cosmógrafos régios, os dois seguiram para Cairo no Egito, um dos maiores centros mulçumanos da época em busca de notícias do mítico reino de Preste João e da Índia. Pêro da Covilhã transportava com ele uma carta de marear onde teria que anotar todas as informações pertinentes dos locais em que ele estivera. Segundo vários historiadores, essa carta continha um rico conhecimento sobre os litorais da costa oriental da África e de algumas partes do continente asiático. Dessa forma, as informações levantadas por Covilhã traziam dados mais precisos e atualizados sobre essas regiões, revelando uma distância bem maior entre Europa e Ásia a partir do Oeste em relação as estimativas de Toscanelli, estudioso que influenciou o projeto de Colombo.
} 
No caso português, o interesse que o motivou a negociar o referido tratado foi o da localização original da linha oficial de demarcação. Insistentemente, D. João II, contestando os privilégios jurídicos concedidos pelo papa à Espanha, uniu a essa situação os seus conhecimentos cosmográficos para mudar a linha oficial mais para oeste, alegando que os navios portugueses estavam constantemente navegando por essas águas e os limites eram muito estreitos. Tal ideia foi apresentada para os espanhóis como uma medida de segurança para a navegação em alto mar ao sul do Atlântico. A delegação espanhola aceitou a mudança. Entretanto, a rainha Isabel ficou bastante desconfiada mediante a solicitação do rei português. Para ela, D. João II estava escondendo alguma informação valiosa. ${ }^{5}$ Para muitos autores, como por exemplo, Jaime Cortesão, o monarca de Portugal suspeitava da existência de terras ao sul do Atlântico. Apesar de carecer de fontes, ele afirma, categoricamente, conforme descrito na nota anterior, que D. João II sabia da existência de terras ao sul do Equador e que a sua insistência em deslocar a raia demarcatória teria sido para proteger seu descobrimento.

Consolidados os acordos, pode-se concluir que a cartografia teve um papel decisivo no desfecho das disputas pelas fronteiras do mundo a descobrir, sendo Tratado de Tordesilhas o ápice de um processo de disputas que nos permite compreender parte considerável da geopolítica do século XVI e, no caso dos impérios ibéricos, até meados do século XVIII. Pois, aparentemente, tal tratado forneceu aos reinos competidores uma solução a uma questão complicada de se resolver e que acabou criando condições para novas disputas, porque os compromissos que foram assumidos perante os acordos assinados em 1494 geraram uma série de inconvenientes para serem debatidos. Afinal, devido à falta de um método confiável para a determinação longitudinal, o traçado de um meridiano de polo a polo não poderia deixar de acarretar a possibilidade da ocorrência de sérios problemas, como se verificou mais tarde.

Em relação a isso, cabe lembrar que a chegada de Pedro Álvares Cabral em 1500 ao território que (depois de alguns nomes) ficou conhecido como Brasil, despertaria novas discussões relacionadas ao meridiano de Tordesilhas, levando o rei Manuel I de Portugal, sucessor de D. João II, a acionar os seus cartógrafos para a elaboração de cartas e planisférios representado as terras portuguesas ao leste da linha divisória do mencionado meridiano, bem como os reis Fernando e Isabel a fazerem o mesmo ao oeste da mesma linha.

Isso permitiu confirmar a tese de que o Tratado de Tordesilhas evidenciou a verdadeira natureza dos mapas produzidos durante os descobrimentos, revelando os seus recursos retóricos e expressões autoritárias de soberania e possessão (SÁNCHEZ, 2013, p. 101), o que o permite

\footnotetext{
${ }^{5}$ Para Cortesão (1960) a insistência de D. João II, muitas vezes em tom ameaçador, em deslocar a linha por mais 100 léguas a oeste, acabou por despertar a curiosidade dos Reis Católicos. Respaldados pelas novas bulas de Alexandre VI, eles ordenaram, através de uma carta expedida em 5 de setembro de 1493, a exploração das terras e ilhas à altura da Guiné e ao sul.
} 
concluir que a representação cartográfica foi a principal ferramenta com que se fez valer a soberania de um império sobre a jurisdição territorial que marcava o seu domínio e que, em muitas ocasiões, estiveram sujeitos a fortes medidas de autoritarismo monárquico

Portanto, grande parte dos planisférios, produzidos durante os primeiros anos do século XVI, não expressavam apenas os descobrimentos. Passaram a revelar, acima de tudo, a soberania de quem os realizou, de forma que essa reorientação política dos mapas concedeu à Espanha e a Portugal uma hegemonia marítima sem precedentes. Afinal, mesmo outras nações da Europa não reconhecendo o Tratado de Tordesilhas, os ibéricos, após anos de disputa, conseguiram moldar uma nova geopolítica legitimando as suas possessões por meio dos mapas, de modo que nos permite concluir, conforme observação de Ravel, que as representações euclidianas do espaço, ao serem transformadas numa paisagem física espacialmente ordenada, estavam "indissociáveis da afirmação do poder monárquico" (REVEL, 1990, p. 144).

\section{CONSIDERAÇÕES FINAIS}

Depois da reformulação dos estudos sobre a história cartográfica, da qual Harley, referência teórica e metodológica principal desse estudo, é um dos maiores expoentes, os horizontes geo-historiográficos desse campo de estudos estão sendo cada vez mais expandidos com pesquisas, como essa, que concebem os mapas como um discurso gráfico capaz de proporcionar aos Estados o exercício de um tipo de poder diplomático, jurídico e simbólico na geopolítica e, de fato, nos territórios por eles controlados, desde o tempos mais remotos das civilizações.

Desse modo, no contexto das Grandes Viagens Oceânicas e do Expansionismo Marítimo, Territorial e Comercial, a renovada cartografia renascentista foi transformada em um eficiente instrumento de legitimação das conquistas ibéricas e de fortalecimento do poder de suas monarquias, que, ao se utilizarem de uma eficiente manipulação das representações cartográficas, resolveram disputas territoriais, ocuparam espaços, demarcaram fronteiras e, dessa maneira, foram construindo seus impérios.

Impérios cujas histórias se revelam nos mapas; esse antigo artefato que, no alvorecer da Idade Moderna, foi convertido em uma das mais estratégicas armas na geopolítica internacional, sendo a experiência portuguesa, nação pioneira nas grandes viagens oceânicas, um dos melhores exemplos de sucesso dessa conversão, que lhe permitiu expandir seu império, consolidar suas posses e reforçar sua posição no complexo emaranhado de disputas ensejadas pela corrida ultramarina dos nascentes Estados Modernos.

Assim, a Cartografia foi fundamental para a expressão do poder monárquico em franco processo de afirmação e consolidação na época renscentista, sobretudo no século XVI, quando a 
expansão marítima e territorrial dos portugueses e espanhóis criaram condições para que os mapas fossem transformados em um poderoso e eficiente instrumento para estabelecer juridicamente os domínios territoriais disputados entre essas nações, cujos representantes no certame geopolítico souberam utilizar deles para fazer valer seus interesses expansionistas e reforçar seus argumentos no jogo diplomático das disputas pelas foronteiras marítimas e territoriais.

\section{REFERÊNCIAS}

ADONIAS, I.; FURRER, B. Mapa: Imagens da Formação Territorial Brasileira. 1. ed. Rio de Janeiro: Fundação Emílio Odebrecht, 1993. 399p.

ALENCASTRO, L. F. A Economia Política dos Descobrimentos. In: A. N. (Org.). A Descoberta do Homem e do Mundo. São Paulo: Companhia das Letras, 1998. p. 193-207.

ANDERSON, B. Comunidades Imaginadas. 1. ed. São Paulo: Companhia das Letras, 2008. 336p.

BARRETO, L. F. Descobrimentos e Renascimento: formas de ser e pensar nos séculos XV e XVI. 1. ed. Lisboa: Imprensa Nacional/Casa da Moeda, 1983. 327p.

. Os descobrimentos e a ordem do saber: uma análise sociocultural. 1. ed. Lisboa: Gradiva, 1987. 106p.

BLACK, J. Mapas e Histórias. Construindo Imagens do Passado. 1. ed. São Paulo: EDUSC, 2005. $424 \mathrm{p}$.

BOURDIEU, P. O Poder Simbólico. 1. ed. Rio de Janeiro: Bertrand Brasil, 1989. 460p.

BOWN, S. R. 1494. 1. ed. São Paulo: Globo, 2013. 329p.

BOXER, C. O império marítimo português: 1415-1825. 2 ed. Lisboa: Edições 70, 2012. 426p.

BROTTON, J. Uma história do mundo em doze mapas. 1. ed. Rio de Janeiro: Zahar, 2012. 616p.

BUESCU, A I. D. João III. 1. ed. Lisboa: Círculo de Leitores, 2008. 416p.

CANAS, A. C. Cartografia náutica portuguesa. 1. ed. Lisboa: Instituto Camões, 2003. 108p.

CASTRO, J. F. M. História da Cartografia e Cartografia Sistemática. 1. ed. Belo Horizonte: Ed. PUCMinas, 2012. 135p.

CHARTIER, R. A História cultural: entre as Práticas e Representações. 2. ed. Rio de Janeiro: Difel, 2002. 244p.

CLAVAL, P. Espaço e Poder. 1. ed. Rio de Janeiro: Zahar, 1979. 248p.

CORTESÃO, A.; TEIXEIRA DA MOTA, A. Portugaliae Monumenta Cartographica. Volume 1. 1. ed. Lisboa, 1960. 2300p.

CORTESÃO, J. História do Brasil nos velhos mapas. 1. ed. Lisboa: Imprensa nacional-Casa da moeda, 1960. 460p. 
Esparsos. 1. ed. Coimbra: Universidade de Coimbra, 1974. 227p.

CROWLEY, R. Conquistadores: como Portugal criou o primeiro império global. 1. ed. São Paulo: Planeta, 2016. 430p.

DIAS, T. A. O espaço cartográfico enquanto escrita do poder. In: SIMPÓSIO BRASILEIRO DE CARTOGRAFIA HISTÓRICA. 2., 2011, Paraty, Anais... Paraty, 2011. p. 26-29.

DIFFIE, B. W.; WINIUS, G. D. A Fundação do Império Português. 1415-1580, vol. 1. 1. ed. Lisboa: Veja, 1999. 128p.

DUTRA, D. P. S. A cultura dos descobrimentos em Portugal: um estudo da relação entre a Sabedoria do Mar e o Conhecimento Acadêmico na Renascença. 2013. 121f. Dissertação (Mestrado em História) - Departamento de História, Universidade Federal Fluminense, Niterói, 2013.

FONSECA, F. P.; OLIVA, J. Cartografia. Coleção: Como eu ensino. 1. ed. São Paulo: Melhoramentos, 2013. 188p.

FOUCAUlT, M. Microfísica do Poder. 8 ed. Rio de Janeiro: Graal, 1989. 432p.

FURTADO, J. F.; SILVA, V. F. The cartographic challenge of the new. 1. ed. Belo Horizonte: Odisseia, 2017. 139p.

GIRARDI, G. Apontamentos para uma cartografia da Cartografia Geográfica brasileira. Revista da ANPEGE, v. 7, n. 1, p. 237-250, 2011.

2012.

. Mapas alternativos e educação geográfica. Revista Percursos, v. 13, n. 02, p. 39-51,

GODINHO, V. M. A expansão quatrocentista portuguesa: problemas das origens e da linha da evolução. 1. ed. Lisboa: Dom Quixote, 2007. 150p.

HARGREAVES, A. O ensino na sociedade do conhecimento: a educação na era da insegurança. 1. ed. Porto: Porto Editora, 2003. 288p.

HARLEY, J. B. (a). Mapas, saber e poder. Confins, n. 5, p. 2-3, 2009.

(b). A Nova História da Cartografia. Mapas, saber e poder. Confins, n. 5, 2009.

. La Nueva Naturaleza de los Mapas: Ensayos sobre la historia de la Cartografia. 1. ed. México: Fondo de Cultura, 2005. 398p.

HARVEY, D. Condição Pós-Moderna. 25. ed. São Paulo: Edições Loyola, 1992. 352p.

JACOB, C. Por uma história cultural da cartografia. Espaço e Cultura, Rio de Janeiro, n. 39, p. 221-236, 2016.

KANTOR, Íris. Usos diplomáticos da ilha-Brasil: polêmicas cartográficas e historiográficas. Vária História, Belo Horizonte, v. 23, n. 37, p. 70-80, 2007. 
LIMA, L. C. Clio em questão: a narrativa na escrita da história. In: RIEDEL, D. C. (Org.). Narrativa, ficção, história. Rio do Janeiro: Imago, 1988.

LESTER, T. A quarta parte do mundo: a corrida aos confins da Terra e a épica história do mapa que deu nome à América.1. ed. Rio de Janeiro: Objetiva, 2012. 544p.

LESTRINGRANT, F. A oficina do cosmógrafo ou a imagem do mundo no Renascimento. Tradução de Edmir Missio. 1. ed. Rio de Janeiro: Civilização Brasileira, 2009. 320p.

LOPES, J. F. R. Cartografia histórica e geopolítica do espaço brasileiro no contexto da colonização da América do Sul (séculos XVI-XVIII). 2016. 321 f. Tese (Doutorado em Geografia) - Instituto de Geografia e Ordenamento do Território, Universidade de Lisboa, Lisboa, 2016.

QUADROS, E. A letra e a linha: a cartografia como fonte histórica. Mosaico, v. 1, n. 1, p. 27- 40, 2008.

RAFFESTIN, C. Por uma geografia do poder. Trad. de Maria Cecília França.1 ed. São Paulo: Ática, 1993. 266p.

REVEL, J. A invenção da Sociedade. 1. ed. Rio de janeiro: Bertrand Brasil, 1990. 592p.

SÁNCHEZ, A. La espada, la cruz y el Padrón: Soberanía, fe y representación cartográfica en el mundo ibérico bajo la Monarquía Hispánica (1503-1598). 1. ed. Madrid: Consejo Superior de Investigaciones Científicas, 2013. 158p.

SANTOS, C. Cartografia Geográfica e Representação Gráfica. 1. ed. Nova Iguaçu: Agbook, 2015. 270p.

SANTOS, D. A reinvenção do espaço. 1. ed. São Paulo: Editora da Unesp, 2002. 218p.

SEEMANN, J. Cartografia e cultura: abordagens para a geografia cultural. In: ROSENDAHL, Z.; CORREA, R. L. (Org.). Temas e caminhos da geografia cultural. Rio de Janeiro: Ed. UERJ, 2010. p. $155-156$.

SERRÃO, J. V. Lusitanidade e Hispanidade: Realidades pioneiras na formação do Estado Moderno. Mare Liberum, n. 10, p. 13-19, 1995.

THOMAZ, L. F. De Ceuta a Timor. 2 ed. Lisboa: Difel, 1998. 780p.

VARGAS, M. A imagem do mundo e as navegações ibéricas. Revista da Sociedade Brasileira de História da Ciência, v. 14, p. 81-95, 1995.

VASCONCELLOS, R. A Cartografia tátil e o deficiente visual: uma avaliação das etapas de produção e uso do mapa. 1993. 268 f. Tese (Doutorado em Geografia) - Faculdade de Filosofia, Letras e Ciências Humanas, Universidade de São Paulo, 1993. 